\title{
Dispersal and phylogeography of the agamid lizard Amphibolurus nobbi in fragmented and continuous habitat
}

\author{
D. A. DRISCOLL*tł and C. M. HARDY* \\ *CSIRO Sustainable Ecosystems, GPO Box 284 Canberra, ACT 2601, Australia, +School of Geography and Environmental Studies, \\ University of Tasmania, Private bag 78, Hobart, TAS, 7007, †School of Biological Sciences, Flinders University, GPO Box 2100, \\ Adelaide, SA 5001, Australia
}

\begin{abstract}
Approximately $90 \%$ of native vegetation has been cleared for agriculture in central New South Wales, Australia. Habitat loss has reduced and fragmented populations of the agamid lizard Amphibolurus nobbi. We compared genetic structure of populations of this species in an unmodified landscape with those from small nature reserves and linear remnants in farming areas. We ask: Is there evidence for reduced dispersal and population fragmentation among farm populations? Using $2008 \mathrm{bp}$ mtDNA sequences and allozyme electrophoresis, we found that small populations in farming areas had as much genetic variation as populations in nature reserves. Application of nested clade analysis (NCA) indicated isolation-by-distance effects among populations from uncleared areas, but not among populations within farming locations. The genetic evidence therefore implied a high level of migration in the cleared landscapes. High dispersal after fragmentation may have resulted from either a burst of movement at the time of land clearing with dragons from many sources finding refuge in a few remnants, or from ongoing rapid dispersal through unsuitable habitat. A phylogeny based on $\mathrm{mtDNA}$ revealed that $A$. nobbi populations in the study area are deeply divided into two reciprocally monophyletic groups. Although we did not sample the entire species range, one of these evolutionarily significant units was only detected in remnant vegetation in the agricultural landscape. Therefore, a substantial subclade of this species may be vulnerable to extinction. Our findings emphasize that local populations of widespread species can harbour important intraspecific genetic diversity, supporting the case for maintaining widespread species throughout production landscapes.
\end{abstract}

Keywords: conservation genetics, corridor, declining species, land clearing, mitochondrial DNA, reptile

Received 22 November 2004; revision accepted 20 January 2005

\section{Introduction}

Extensive land clearing leading to habitat loss and fragmentation renders populations of many species isolated and diminished in size (Saunders et al. 1991; Lande 1998). Populations that become isolated in remnant habitat face a substantial risk of extinction (Bolger et al. 1997). However, species that are able to disperse through the modified landscape may survive in a series of patchy populations, or as a metapopulation (Harrison 1991; Hanski 1998). Therefore, understanding the dispersal capacity of a species after habitat fragmentation is important for predicting survival

Correspondence: Dr Don Driscoll, Fax: +61 88201 3015; E-mail: don.driscoll@flinders.edu.au in extensively cleared farming landscapes (Cooper et al. 2002; Cale 2003).

When populations become isolated and thereby reduced in size, the rate of genetic drift is expected to increase (Wright 1931). Genetic drift leads to both increased divergence among populations and reduced genetic variation within them (Wright 1931). Therefore, genetic methods can provide evidence for population subdivision in fragmented landscapes (Moritz 1994a; Williams et al. 2003). For example, isolated and fragmented populations of the Swedish sand lizard (Lacerta agilis) had lower genetic variation compared with the same species from Hungary, where its distribution was more continuous (Gullberg et al. 1998). Knutsen et al. (2000) reported a similar pattern for a tenebrionid beetle, with genetic divergence among 
populations three times greater in an agricultural setting compared to those in continuous habitat.

In addition to addressing questions of dispersal, genetic methods have other applications in species conservation (Moritz 1994a). Recognition of evolutionarily significant units (ESUs) highlights where intraspecific biological diversity resides, complementing existing knowledge of species and subspecies boundaries (Fraser \& Bernatchez 2001; Moritz 2002). Furthermore, phylogeographical analyses have the capacity to infer historic processes of evolution (Avise et al. 1987; Templeton 1998). Effective biodiversity conservation includes both the representation of all genetic groups (ESUs) in reserves, and the maintenance of evolutionary processes (Rojas 1992; Moritz 2002). Fine-scale examination of population genetic structure can reveal likely evolutionary processes and therefore provide a valuable guide for conservation management (Driscoll 1998).

The agamid lizard Amphibolurus nobbi has undergone extensive declines in agricultural landscapes of central New South Wales, Australia (Driscoll 2004). This species was only detected in reserves and in one category of linear remnant (ungrazed strips of vegetation 30-100 m wide on paddock margins). This resulted in the area of occupancy being reduced at two locations to $22 \%$ of remnant vegetation, and the distribution of $A$. nobbi appeared substantially fragmented. The abundance of $A$. nobbi was lower in reserves in the agricultural setting than in continuous habitat, and there was evidence of reduced allozyme variation at one of three sites compared with populations in uncleared habitat. These patterns raised concerns that remnant $A$. nobbi populations may be isolated and headed towards extinction (Driscoll 2004).

In this study, we use mtDNA sequences and allozyme data to examine the population genetic structure of $A$. nobbi from three agricultural locations and one uncleared location. We use these data to address three questions:

1 Is there evidence of reduced dispersal and population isolation in the agricultural landscape compared with populations in an uncleared landscape?

2 Is there any phylogeographical pattern among $A$. nobbi populations, and what does it reveal about dispersal patterns?

3 Given the answers to questions 1 and 2, what are the implications for conserving genetic diversity and maintaining evolutionary processes?

\section{Materials and methods}

\section{Samples}

There are two subspecies of Amphibolurus nobbi that have non-overlapping distributions: Amphibolurus nobbi nobbi in northeast New South Wales and southeast Queensland, and Amphibolurus nobbi coggeri in southwest New South Wales, northwest Victoria and southeast South Australia (Cogger 1996). Adult A. nobbi have snouth-vent lengths ranging 50-75 mm (see Plate 1, Driscoll 2004 for photograph). In A. n. nobbi, eggs are laid in spring and autumn, and autumn clutches hatch the following spring (Witten 1974).

Amphibolurus nobbi coggeri samples were available from 14 of the 36 sites sampled by Driscoll (2004) (Fig. 1). Sample sites included four locations: Nombinnie, Pulletop, Gubbata and Taleeban. The latter three locations consisted of small rectangular reserves of remnant mallee vegetation and a network of linear remnants in an agricultural matrix. Mallee plant communities are dominated by multistemmed Eucalyptus species (mallee growth form), with some Callitris glaucophylla and have a shrubby understorey (Sivertsen \& Metcalfe 1995). Approximately $90 \%$ of the native vegetation had been cleared for cropping and sheep production, a process that began in the early 1800s, but was completed with a surge in and clearing in the 1970s (Bauer \& Goldney 1999). At the three agricultural locations, samples were obtained from two sites within the Gubbata and Taleeban reserves and one site in the Pulletop reserve. At each agricultural location, an additional sample was obtained from ungrazed linear remnants with spinifex understorey (Triodia scariosa, a clumping prickly grass). Amphibolurus nobbi only occurred in linear remnants if they were ungrazed and had spinifex in the understorey (Driscoll 2004). The Nombinnie location included six sample sites, all within an uncleared mallee landscape (Fig. 1). Sample sizes are indicated in the Results (Fig. 6).

Two toes were removed from each animal as part of a mark-recapture study in January, February, and OctoberDecember in 1999, and January in 2000 (see Driscoll 2004 for details). Toes were stored in liquid nitrogen in the field and transferred to a $-70^{\circ}$ freezer.

The samples collected were of the subspecies A.n.coggeri (Cogger 1996). One additional sample, of subspecies $A$. $n$. nobbi, was obtained from the Australian National Wildlife Collection (CSIRO Sustainable Ecosystems, Canberra) and originated approximately $1240 \mathrm{~km}$ NNE of Nombinnie (6.5 km NNW of Crab Camp, Shoalwater Bay army training area, north of Rockhampton, Queensland, 22 $35^{\prime} 21^{\prime \prime} \mathrm{S}$, $\left.150^{\circ} 42^{\prime} 22^{\prime \prime} \mathrm{E}\right)$.

\section{DNA isolation and sequencing}

A modified hexadecyl trimethyl ammonium bromide (CTAB) protocol (Sambrook et al. 1989) was used to extract DNA. Polymerase chain reaction (PCR) was conducted under mineral oil in $100-\mu \mathrm{L}$ total volume containing less than 1-10 ng of DNA, $1 \mu \mathrm{M}$ each primer, $1.5 \mathrm{~mm} \mathrm{MgCl}_{2}$, $200 \mu \mathrm{M}$ dNTPs and 1-2 units of Taq DNA polymerase (Gibco BRL) in the reaction buffer provided by the manufacturer (20 mM Tris- $\mathrm{HCl}, \mathrm{pH} 8.4,50 \mathrm{mM} \mathrm{KCl}$ ) and 


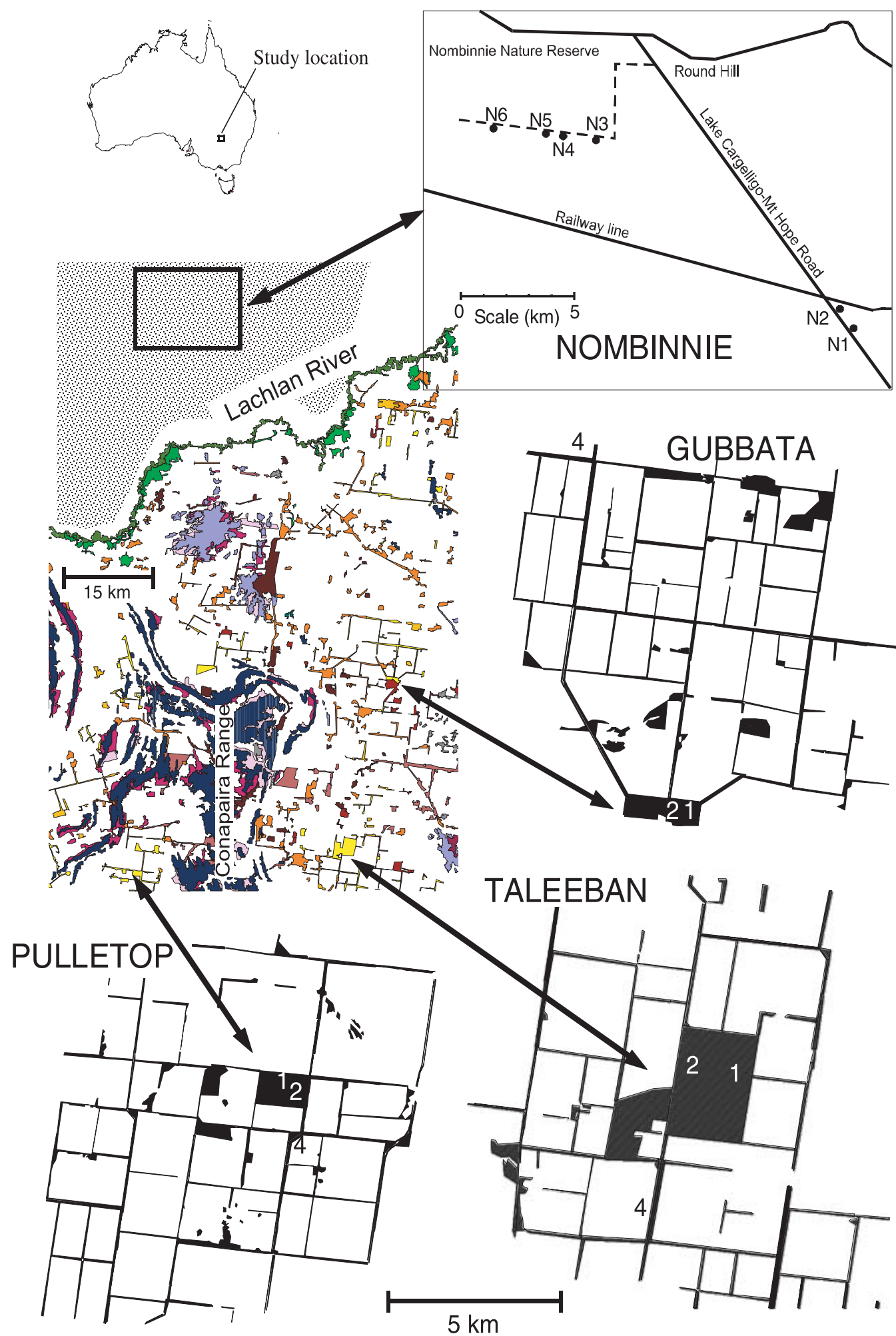

Fig. 1 Three agricultural locations (Pulletop, Gubbata, Taleeban) and one uncleared location (Nombinnie) were studied. Samples were available from sites within reserves [numbered 1, 2 (site 2 only at Pulletop)] and from a linear remnant (numbered 4) at each location. Six sites were sampled in continuous mallee (N1-N6). Remnant vegetation map after Sivertsen \& Metcalf (1995). Stippling represents an area

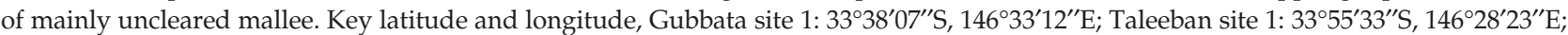
Pulletop site $1: 33^{\circ} 57^{\prime} 57^{\prime \prime} \mathrm{S}, 146^{\circ} 04^{\prime} 46^{\prime \prime} \mathrm{E}$, Nombinnie site N1: $32^{\circ} 59^{\prime} 08^{\prime \prime} \mathrm{S}, 146^{\circ} 03^{\prime} 14^{\prime \prime} \mathrm{E}$. 
using a FTS 320 cycle sequencer (Corbett Research). Two universal squamate primers were used to isolate a 2000-base segment of mtDNA: $t R N A-L e u$ (heavy strand, $5^{\prime}$-TACTTTTACTTGGATTTGCACCA-3'), and ND3l (light strand, 5'CCCTACGAATGTGGCTTCGACC-3') (Scott \& Keogh 2000). PCR cycling included an initial cycle with denaturing at $95^{\circ} \mathrm{C}$ for $3 \mathrm{~min}$, annealing at $50^{\circ} \mathrm{C}$ for $1 \mathrm{~min}$ and $45^{\circ} \mathrm{C}$ for $1 \mathrm{~s}$, followed by an extension at $72{ }^{\circ} \mathrm{C}$ for $1 \mathrm{~min}$. The subsequent 39 cycles were the same except for an initial denaturing at $92{ }^{\circ} \mathrm{C}$. Each reaction was completed with a final extension at $72{ }^{\circ} \mathrm{C}$ for $10 \mathrm{~min}$. PCR-amplified DNA fragments were run on $1 \% \mathrm{w} / \mathrm{v}$ flat-bed agarose gels and fragments excised and purified using a Nucleotrap kit (Macherey-Nagel, DD52313) for further subcloning or direct sequencing.

DNA fragments from two A. nobbi coggeri taken from extremes of the sample range (populations P2 and N3, field codes 724, 445, respectively) were obtained by PCR then cloned into the pGEM-T Easy plasmid vector (Promega) in Escherichia coli strain XL1-Blue (Stratagene). The cloned fragments were sequenced using the $t R N A-L e u, N D 3 I$ and ND4I primers (ND4I: light strand 5'-TGACTACCAAAAGCTCATGTAGAAGC-3'; Ian Scott, personal communication). The complete sequences for 724 (GenBank Accession no. AY280456) and most of 445 (GenBank AY280457) were obtained between primers $t R N A$-Leu and ND4I. Subsequently, the fragment was sequenced in three sections directly from the purified PCR product for all animals, using a combination of primers (Table 1) developed from the cloned sequences. We used BigDye Terminator Cycle sequencing, run on an automated sequencer. Reliable sequences were only obtained for all animals for nucleotides 92-2098 relative to the sequence for 724-P2 (GenBank AY280456). Some animals (not those that were clones) had a 90-base duplication with no internal mutations, so it was reduced to a single position for analysis, with a gap for animals without the duplication. The total length of sequence analysed for each animal was $2008 \mathrm{bp}$.

Table 1 Primers used in obtaining c. 2000 bp of sequence for 94 Amphibolurus nobbi. Primer names include the gene in which they reside, a letter indicating if they run forwards $(\mathrm{F})$ (designated as $5^{\prime}$ to $3^{\prime}$ on the light strand) or in reverse (R), and a number to distinguish among primers in the same gene

\begin{tabular}{lcl}
\hline Primer name & $\begin{array}{l}\text { Position } \\
\text { (base number) }\end{array}$ & Sequence \\
\hline ND3F2 & $3-21$ & 5'-CTTTAAAATTCACGCCTAC-3' \\
ND3F6 & $33-51$ & 5'-CACTTCTTTCTAATCGCAA-3' \\
ND4F3 & $734-752$ & 5'-TAGCCATAGACCAAATCTC-3' \\
ND4R3 & $944-927$ & 5'-AAGGTGGCTTCGAATGAG-3' \\
ND4F2 & $1480-1498$ & 5'-ATAAGCATTTCAGGAACAA-3' \\
ND4F & $1505-1522$ & 5'-TAATAATAGCCCACGGAC-3' \\
ND4R & $1559-1542$ & 5'-AATATGTTGGCGAGGCAG-3' \\
ND4R2 & $1707-1689$ & 5'-GATGATGGTGAGTTCTCCT-3
\end{tabular}

The presence of the duplicated sequence in some animals might indicate that the PCR products were derived from a nuclear rather than mitochondrial copy of the mitochondrial genome. We can however, discount this possibility because, first, only single PCR products were produced from individual animals rather than two products differing by $90 \mathrm{bp}$ as would be expected if a genomic fragment was present. Second, the number of cycles required to produce PCR fragments was identical between animals with the duplication and those without. This is not expected if a single nuclear copy rather than multiple mitochondrial copies of the sequence were the target for the PCR. Finally, sequence analysis reveals that the derived protein sequences surrounding the repeat contained complete open reading frames with nucleotide differences confined to silent sites within the codons. All these facts indicate that the sequence was derived from a functional mitochondrial genome as opposed to a nonfunctional nuclear copy.

\section{Analysis}

Sequences for 94 animals (GenBank AY281158-AY281251) were aligned by eye using the program GENEDOC 2.5 (K. B. Nicholas \& H. B. Nicholas, GeneDoc: a program for editing and annotating multiple sequence alignments, distributed by the authors, 1999). Additional manipulation and analysis was performed using VECTOR NTI (InforMax) or Basic Local Alignment Search Tool (BLAST) (Altschul et al. 1990) and ENTREZ software (Schuler et al. 1996).

Neutrality of mutations are assumed in most of the analyses we used, so we applied Tajima's test (Tajima 1989) to determine if the mutations in our data set varied significantly from a neutral pattern, using DNAsP 3.53 (Rozas \& Rozas 1999). We applied the partition homogeneity test with heuristic search using PAUP 4.0 beta version 10 (Swofford 2002) to determine if the rate of evolution varied significantly between different segments of the mtDNA, and therefore whether it was appropriate to combine the entire sequence for analyses (Bull et al. 1993). We tested for differences between the first and second halves of the sequence, tested for differences among genes by partitioning the sequence into coding regions (position 92-125, 281-1909) and noncoding regions (217-280, 1935-2099), and tested for differences between the ND4 gene (565-1909), and the rest of the sequence. In the latter two analyses, positions 1910-34 were excluded because it represents a ND4 coding sequence that is duplicated as a noncoding region in some individuals.

Phylogenetic analysis was performed using MEGA 2.1 (Kumar et al. 2001). A neighbour-joining (NJ) tree (Saitou \& Nei 1987) was formed using Kimura 2-parameter model (Kimura 1980) as the distance measure. The reliability of each node in the phylogeny was assessed using the bootstrap method (Felsenstein 1985). To further examine the 
robustness of conclusions drawn based on the NJ tree, we also used a maximum-parsimony (MP) analysis, with the most-parsimonious trees established using the closeneighbour-interchange method (Nei \& Kumar 2000). We condensed all trees of equally smallest length into a majority-rule consensus tree. Amphibolurus nobbi nobbi was used as the outgroup, and to allay concerns that a subspecies may not be an appropriate outgroup, we also formed an NJ tree with the addition of an Iguana iguana sequence (GenBank AJ278511, nucleotides 9683-11722, Janke et al. 2001).

\section{Nested clade analysis}

We used nested clade analysis (NCA) (Templeton 1998, 2004) to identify significant geographical relationships among haplotypes. A nested cladogram was produced using TCS version 1.13 (Clement et al. 2000) and the nesting structure developed by following the nesting rules of Templeton et al. (1987) and Templeton \& Sing (1993). We then used GEODIs 2.2 (Posada et al. 2000) to perform the NCA, and the results were interpreted using the July 2004 version of the inference key (Templeton 2004).

\section{Divergence and loss of genetic variation}

Divergence among sites was examined using pairwise $F_{\mathrm{ST}}$ values (Weir \& Cockerham 1984), where statistically significant divergence was determined using 10000 permutations of haplotypes between populations (Schneider et al. 2000). Regressions of $F_{\mathrm{ST}}$ vs. distance were performed for four separate classes of pairwise comparisons: between sites at Nombinnie; between sites within each agricultural location; between sites from separate agricultural locations; between sites from Nombinnie and sites from agricultural locations. The significance of differences in slopes and intercepts of the regressions between the four classes was determined using a permutation method (Good 1994) with 5000 permuted data sets, and implemented in the computer package $\mathbf{R}$ (www.r-project.org/). P values represent the proportion of bootstrapped results in the tail of the distribution beyond the actual value, so are one-tailed test probabilities.

We expected that genetic variation might be lost from the small A. nobbi populations in linear remnants at a faster rate than in the reserves, and that the reserves would lose variation at a faster rate than in continuous mallee. A permutation method (Good 1994; Driscoll 2004) with 5000 iterations was used to test for lower variation in linear remnants compared with reserves, and lower variation in reserves compared with continuous mallee. We tested the significance of the difference between the number of haplotypes/animal in linear strips compared with reserves and reserves compared with continuous mallee. In the latter comparisons, we used data from the site with the largest sample size, N3, as representative of Nombinnie populations. Pooling data from separate Nombinnie sites was inappropriate because there was evidence of significant mtDNA divergence between sites.

\section{Allozymes}

Although allozymes have less resolution at an intraspecific level compared with DNA methods (e.g. Shaw et al. 1999), they are a much less expensive and less time-consuming method for examining nuclear genes than DNA sequence analysis. Mitochondrial DNA is maternally inherited and so genetic structuring observed in mtDNA could be largely due to female dispersal patterns (Hillis et al. 1996). Examination of nuclear genes can provide an indication of whether the genetic structuring in mtDNA is due to female dispersal only, or whether it is likely to represent dispersal of populations in general.

Electrophoretic protocols followed Richardson et al. (1986), and included eight loci. Some populations were pooled to increase sample sizes and therefore obtain a better estimate of allele frequencies. Samples pooled included G1 with G2, T1 with T2, N1 with N2, and N4 with N5 and with N6. Sample sizes per locus and allele frequencies are given in the Appendix.

We used exact tests (GENEPOP version 3.3, Raymond \& Rousset 1995a; b) to determine if allele frequencies differed between pairs of populations. The Markov chain parameters were dememorization steps $=1000$; batches $=100$; iterations per batch $=1000$. Nei's (1978) unbiased genetic distance was used to estimate the magnitude of divergence between population pairs, and was used as the distance matrix in a multidimensional scaling analysis (s-stress convergence = 0.0001, min s-stress $=0.0005$, $\max$ iterations $=50$, sPss 11.5.1, www.spss.com). A two-dimensional solution adequately represented the distance matrix. We used the bootstrap step of BIOsys2 (Swofford et al. 1997) to obtain 10000 replicate tables of pairwise genetic distance (Nei 1978). The NEIGHBOUR and CONSENSE programs of PHYLIP (version 3.6a2.1, Felsenstein 2001) were then used to produce a majority rule consensus tree, applying the NJ method.

\section{Results}

Partition homogeneity tests indicated no significant variation among different segments of the 2008-bp sequence analysed, so the entire sequence was used in subsequent analyses. Tajima's test indicated that mutations in the data set were not significantly different from a neutral mutation model (Tajima's $D=-1.45, P>0.1$ ).

There were 82 variable sites, 29 of which were fixed differences between animals from Nombinnie compared with the agricultural sites (Table 2). There were an additional two sites with deletions, and a duplication of $90 \mathrm{bp}$ containing part of the ND4 gene and the $t R N A$ His gene (Table 2). 
Table 2 Forty haplotypes were recognized (labelled in the first column) among the 93 Amphibolurus nobbi (excluding the Queensland sample). There were 56 variable sites (shown in this table, position number in the first row) in addition to 29 fixed differences between Nombinnie and agricultural locations (not shown). Haplotypes with a gap at position 1910 did not have a 90-bp duplicated section of the $t R N A$ His gene, while those with an A in that position did have the duplication (the full duplication is not shown)

$\begin{array}{llllllllllllllllllllllllllllllll}1 & 1 & 1 & 1 & 1 & 1 & 1 & 1 & 1 & 1 & 1 & 1 & 1 & 1 & 1 & 1 & 1 & 1 & 1 & 1 & 1 & 2 & 2 & 2 & 2 & 2\end{array}$

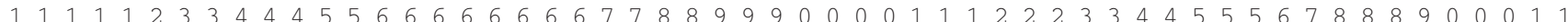

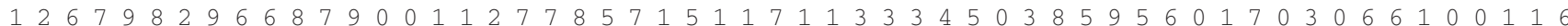

88191784344646916913402325654715048067757791224516005515

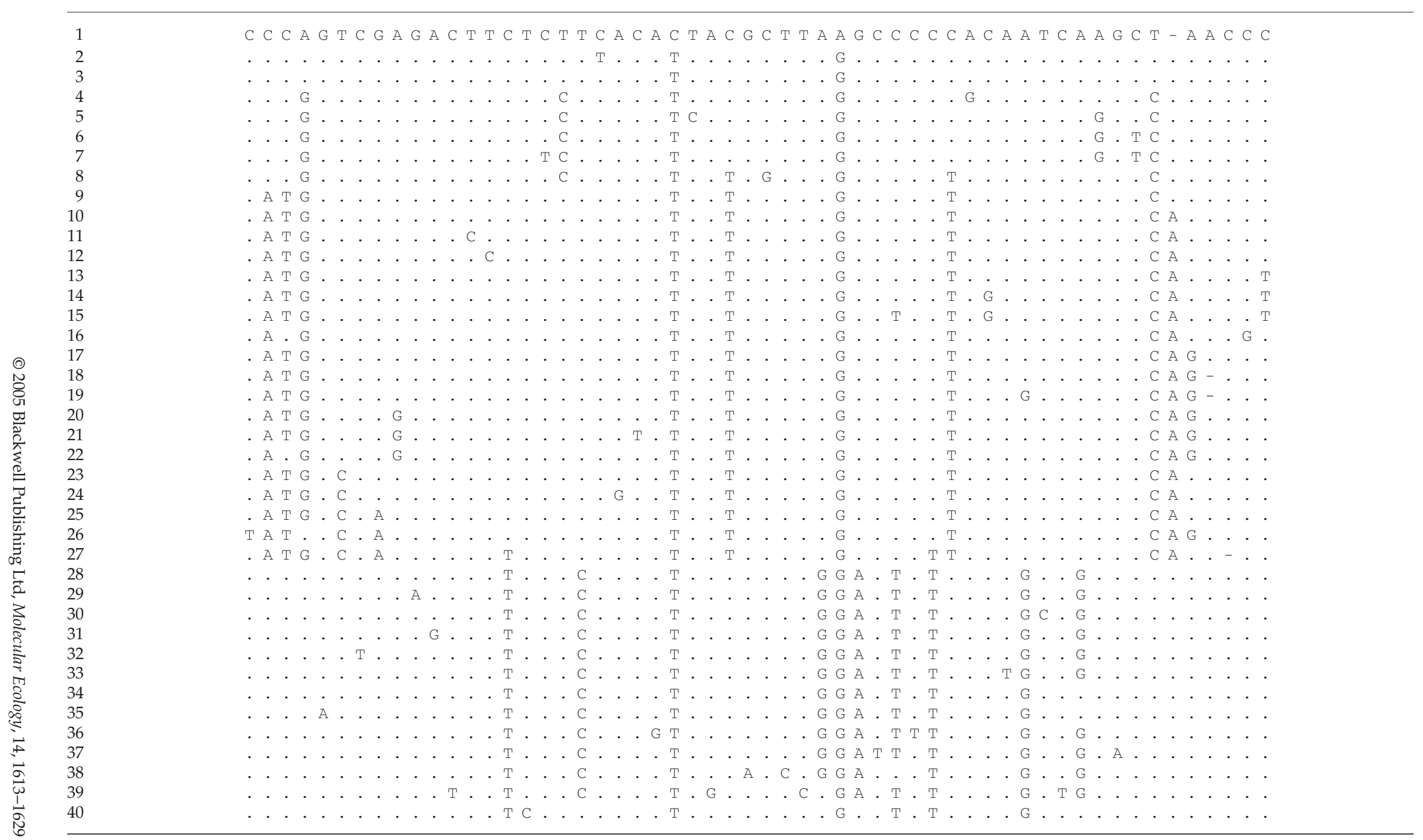


The Amphibolurus nobbi nobbi from Queensland was most closely aligned with the Nombinnie $A$. nobbi coggeri populations, sharing 18 of the 29 fixed differences between Nombinnie and the agricultural populations. However, it also differed from haplotype 28 , the most common haplotype at Nombinnie, at 176 sites, a level of divergence (8.7\%) that is consistent with species-level divergence in other reptile groups (Kraus et al. 1996; Forstner et al. 1998). The Queensland haplotype therefore provides a reasonable outgroup, particularly given it has a separate geographical range to A. n. coggeri, so is likely to represent a historical partition.

\section{Phylogeny}

Using $A$. nobbi nobbi as the outgroup indicated that the phylogeny was most appropriately rooted along the branch separating the Nombinnie clade from the agricultural locations (Fig. 2). The position of the root was confirmed using the Iguana sequence. The most important trends evident in the phylogeny are the deep divergence between A. nobbi from Nombinnie and those from the agricultural landscape, and the separation of Pulletop animals from the Taleeban and Gubbata sites. An important exception to this pattern was the presence of one Taleeban animal with a typical Pulletop haplotype (haplotype 3, Fig. 2). There was a large clade that was relatively unresolved and included haplotypes 9-27. Animals with these haplotypes were from the Gubbata or Taleeban sites (Fig. 2) and were most strongly defined by substitutions at positions 128 and 161 (Table 2). The 90 base pair duplication was also entirely confined to this large Gubbata-Taleeban clade (Table 2). Both the MP analysis and the NJ trees showed the same major patterns.

\section{Nested clade analysis}

The nested cladogram did not link the Nombinnie clade with the agricultural sites. The large number of mutational steps between these groups meant that the link exceeded the 95\% confidence interval for parsimonious connections used by the Tcs program. However, interior and tip clades need to be identified to apply the inference key of Templeton (2004). This is particularly important for interpreting patterns within clade 3-3, 3-2 and 4-1 (Fig. 3). The least divergent representatives from the ancestral state in the NJ tree (Fig. 2) are haplotypes 1 and 40 from the agricultural areas and Nombinnie, respectively. Clade 2-9 (containing haplotype 40) is therefore connected to clade 2-7 (the Pulletop haplotypes 1, 2 and 3, Fig. 3). Following from that connection, we designate clade 2-9 as an internal node of the 3-3 clade, and clade 2-7 as an internal node of the 3-2 clade. We have not altered the interior/tip classifications at lower nesting orders. Without the link, clades 3-2, 3-3 and 4-1 cannot be properly interpreted using the key, despite there being significant phylogeographical structure.

Nested clade analysis identified eight clades with significant geographical associations (Fig. 4). In four clades from lower nesting levels, isolation by distance with restricted gene flow was inferred (Table 3). Clades 1-6 and 2-2 suggested there was a significant pattern of isolation by distance among populations from the Gubbata and Taleeban sites (Table 3, Figs 3 and 4), at a spatial scale of 33-37 km. However, among Nombinnie sites, isolation by distance was evident at an even smaller spatial scale, including clades 1-18 (populations N3, N4, N5, maximum distance $2.1 \mathrm{~km}$ ), and 1-19 (all Nombinnie populations, maximum distance $17.5 \mathrm{~km}$, Table 3, Figs 3 and 4).

At a deeper nesting level (clade 3-3), there was evidence of historical range expansion among the Nombinnie sites (Table 3, Fig. 4). This pattern was evident from the widespread haplotypes in the tip clade 2-8 which had significantly large $D_{\mathrm{c}}$ and $D_{\mathrm{n}}$ values (2-8 includes all Nombinnie populations, Figs 3 and 4), compared with the more restricted geographical range of the interior clade 2-9, which had significantly small $D_{\mathrm{c}}$ and $D_{\mathrm{n}}$ values (2-9 includes only N3, N4 and N5).

Table 3 Application of the inference key from Templeton (2004) to clades with significant geographical association identified significant isolation by distance at small geographical scales, and either fragmentation or isolation by distance at the largest geographical scale

\begin{tabular}{lll}
\hline Significant clade & Key sequence & Inference \\
\hline $1-6$ & $1,2,3,4$ & $\begin{array}{l}\text { restricted gene flow with isolation by distance } \\
\text { unable to distinguish between fragmentation, range } \\
\text { expansion or isolation by distance }\end{array}$ \\
$1-9$ & $1,2,3,5,15,16,18$ & $\begin{array}{l}\text { restricted gene flow with isolation by distance } \\
\text { restricted gene flow with isolation by distance }\end{array}$ \\
$1-18$ & $1,2,3,4$ & restricted gene flow with isolation by distance \\
$1-19$ & $1,2,3,4$ & isolation by distance with or without long distance dispersal \\
$2-2$ & $1,2,3,4$ & (cannot determine without samples between locations) \\
$3-2$ & $1,2,3,5,6,7,8$ & contiguous range expansion \\
& $1,2,11,12$ & restricted gene flow with isolation by distance \\
allopatric fragmentation (assuming A. nobbi absent along Lachlan River)
\end{tabular}



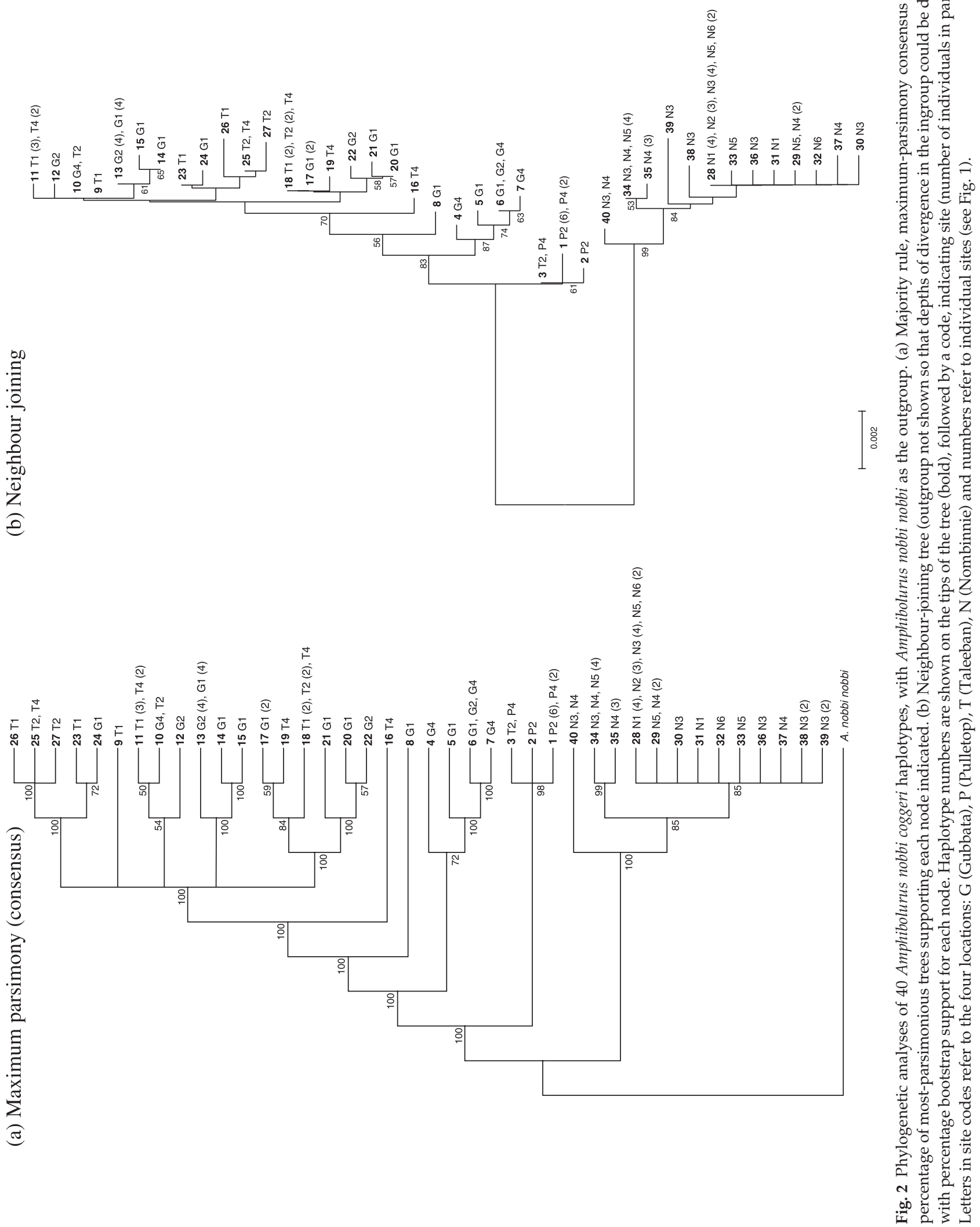


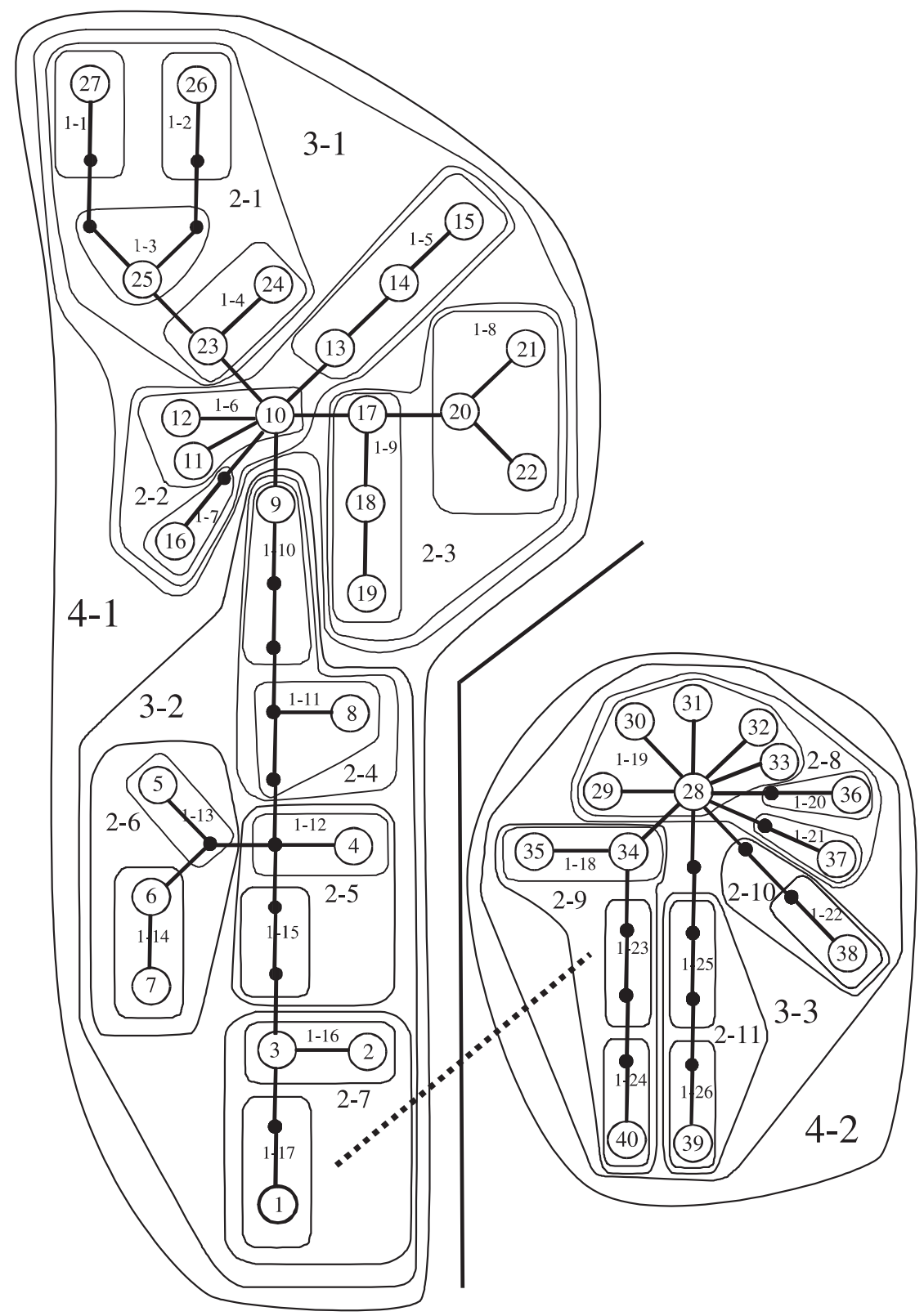

Fig. 3 Haplotype network and nesting structure for 40 Amphibolurus nobbi haplotypes, where the probability of parsimony of each connection exceeds 95\% (Clement et al. 2000). Nested clades are designated using a twonumber system, where the first number refers to clade order, and the second number defines individual clades. The broad black line indicates that the probability of parsimony did not exceed $95 \%$ for connections between clades 3-3 (all Nombinnie populations) and 3-2, because of the very large number of substitutions separating these clades. The dashed line indicates the connection that we have used with the inference key and was based on the phylogeny (Fig. 2).

The significant association of geographical distance with haplotype distribution in clade 3-2 was due to either isolation by distance or long-distance dispersal, and isolation by distance among all agricultural sites was inferred by the genetic structure of clade 4-1 (Table 3). Allopatric fragmentation was inferred for the total cladogram, assuming that $A$. nobbi were absent from areas between sampling locations (Table 3).

\section{Divergence and genetic variation}

Consistent with evidence for isolation by distance effects among Nombinnie populations, there were also significant differences in some of the pairwise $F_{\mathrm{ST}}$ comparisons (Table 4).
Population N4 was significantly divergent from N1, N2 and N3, and population N5 was significantly divergent from N1 and N3. The geographical distance between these population pairs is very small, from 15.3 to $1.6 \mathrm{~km}$ (Table 4). Populations within each of the agricultural locations were not significantly divergent, although there were many significant differences between locations (Table 4).

The slopes of $F_{\mathrm{ST}}$ vs. distance were the same for within Nombinnie and within agricultural locations, however, the intercept was significantly lower for the data comparing sites within agricultural locations (Fig. 5, Table 5), implying higher gene flow. The regression of $F_{\mathrm{ST}}$ and distance between sites at separate agricultural locations had an intermediate intercept and a lower slope compared with 


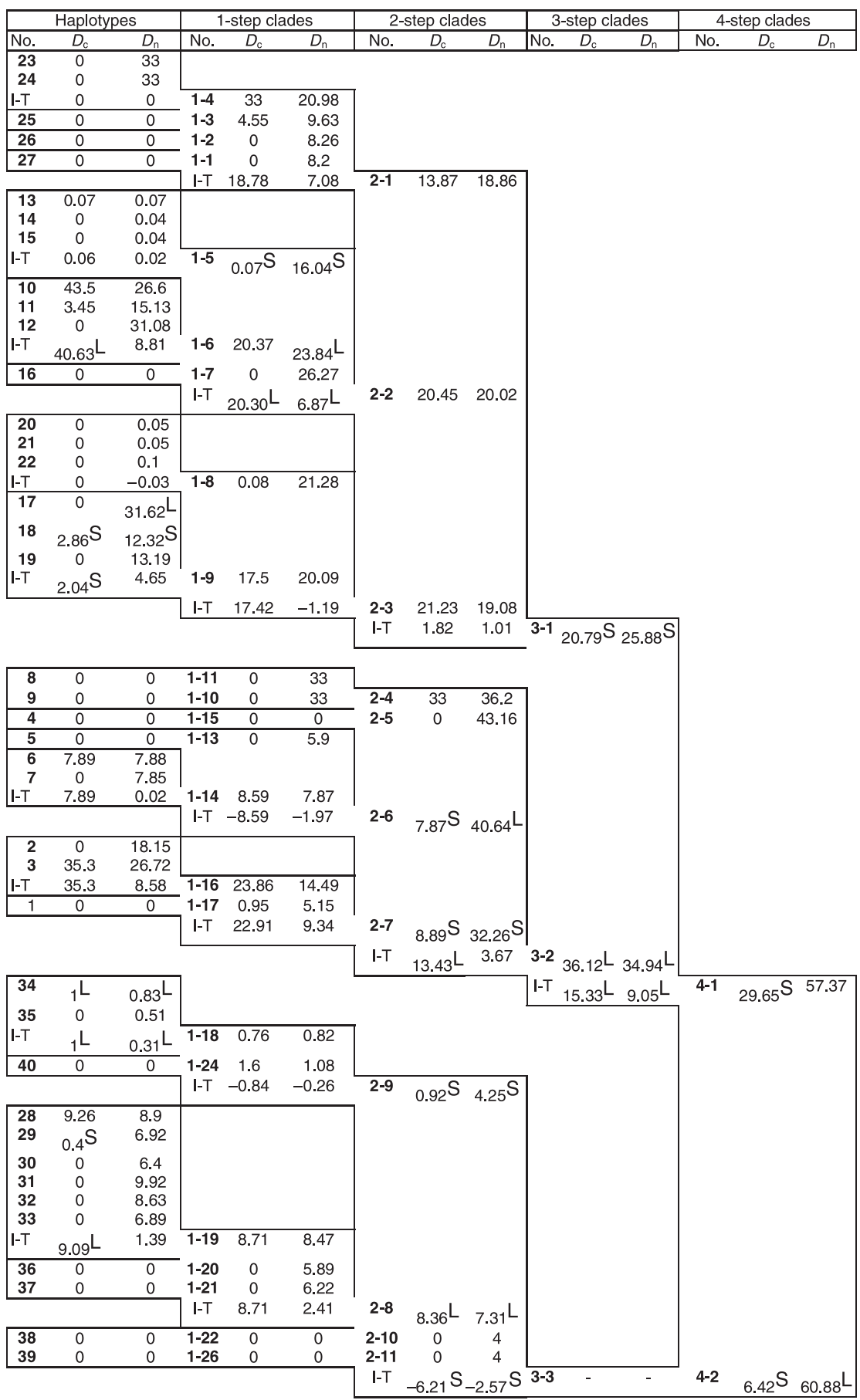

Fig. 4 Haplotypes within eight clades plus the entire cladogram showed significant relationships with geographical distance that were either significantly larger than expected (superscript L) or significantly smaller (superscript S). Individual haplotypes appear at the left of the figure, followed by the 1-step, 2-step, 3-step and 4-step clades. The clade distance $\left(D_{c}\right)$ is the average distance $(\mathrm{km})$ between haplotypes within the clade, while the nested clade distance $\left(D_{n}\right)$ is the average distance of haplotypes in the clade of interest from the geographical centre of haplotypes within the clade at the next higher nesting level (Templeton 1998). These parameters allow the recognition of unusually widespread clades and unusually geographically restricted clades. The average difference between interior and tip clades (I-T) is also given.

the within-Nombinnie or within-agricultural data sets and the slope comparisons had low $P$ values (Fig. 5, Table 5), suggestive of higher gene flow. The regression of $F_{\mathrm{ST}}$ and distance comparing sites from the agricultural locations with sites from Nombinnie showed a slope of approximately zero and high intercept (Fig. 5). Permutation tests imply that the slope and intercepts are significantly different from all other comparisons with one exception, where the $P$ value was 0.052 (Table 5).

\section{Genetic variation}

Permutation tests indicated there was not a significant reduction in haplotype diversity between populations of A. nobbi in linear remnants compared with those in nearby reserves $(P=0.54,0.59,0.23$ for, respectively, P2 cf. P4; T1 and T2 cf. T4; G1 and G2 cf. G4). Although not significant, the trend was towards higher diversity in the small linear remnants, which is contrary to expectations (Fig. 6). 


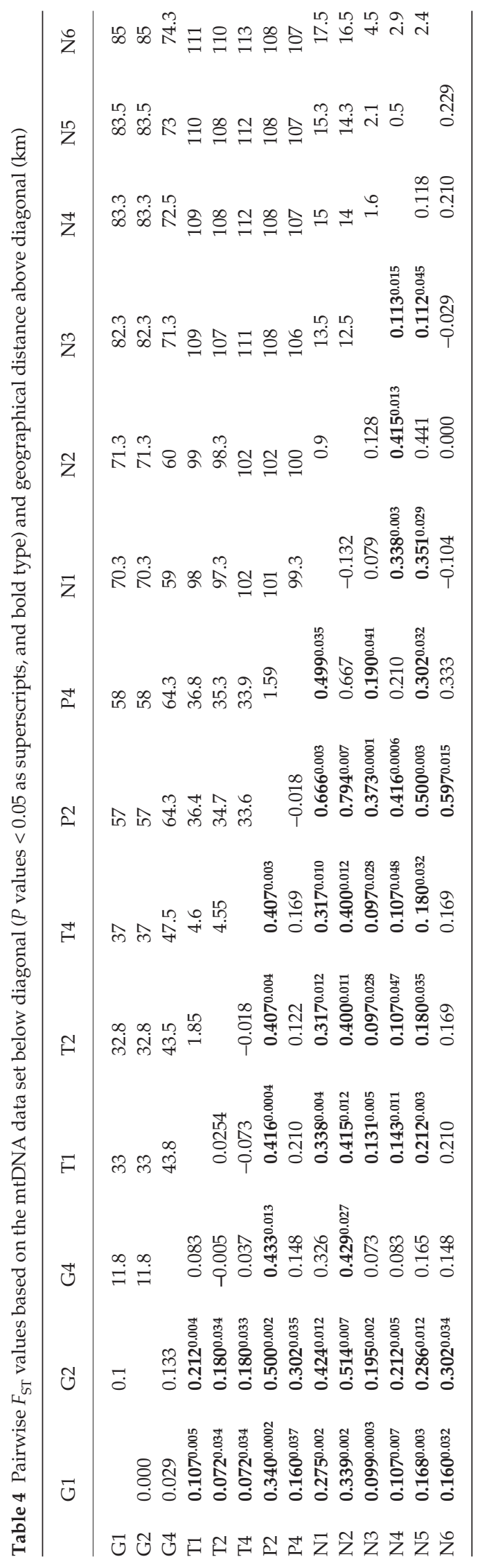

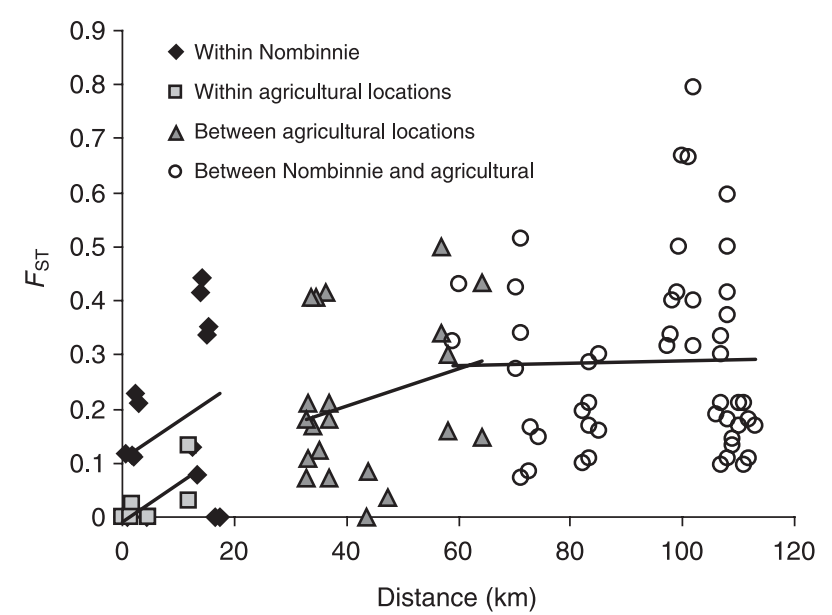

Fig. 5 Genetic differentiation $\left(F_{\mathrm{ST}}\right)$ vs. distance for four classes of pairwise comparisons: between sites at Nombinnie (within Nombinnie, black diamonds); between sites within each agricultural location (within agricultural locations, grey squares); between sites from separate agricultural locations (between agricultural locations, grey triangles); between sites from Nombinnie and sites from agricultural locations (between Nombinnie and agricultural locations, open circles). Regression lines for each class of comparison are shown.

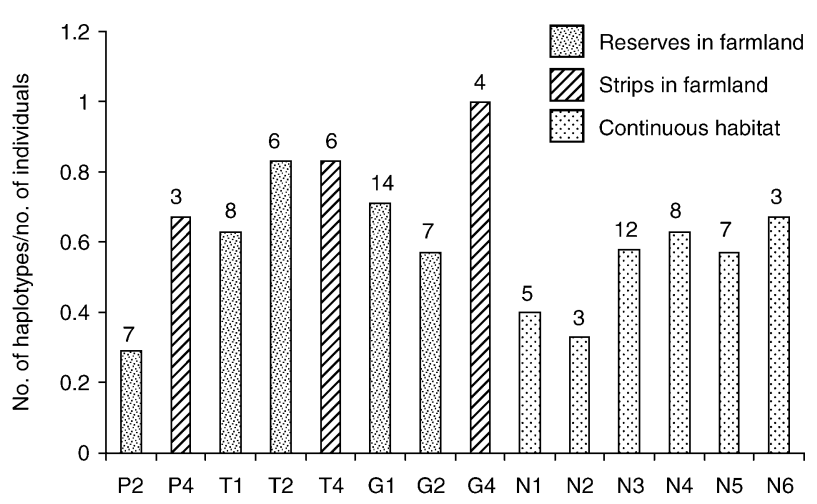

Fig. 6 The average number of haplotypes per individual at three agricultural locations (G, Gubbata; P, Pulletop; T, Taleeban) and continuous mallee at Nombinnie (N). Sample sizes at each site are indicated on the graph. Refer to Fig. 1 for individual site numbers.

Comparison of N3 in continuous mallee with reserves in the agricultural matrix gave conflicting results. Haplotype diversity was not significantly different at Gubbata compared with N3 $(P=0.635)$, but Taleeban had significantly higher haplotype diversity $(P=0.022)$, and Pulletop had significantly lower haplotype diversity than N3 $(P=0.018)$.

\section{Allozymes}

Like the mtDNA patterns of divergence, there were many significant differences between the uncleared (Nombinnie) and the agricultural sites (13 of 18 comparisons, Table 6). 


\begin{tabular}{llcc}
\hline & Comparison & P slope & P intercept \\
\hline Within Nombinnie & Within agricultural & 0.4842 & 0.0494 \\
Within Nombinnie & Between agricultural & 0.0776 & 0.3340 \\
Within agricultural & Between agricultural & 0.0712 & 0.1056 \\
Within agricultural & Between Nombinnie and agricultural & 0.0082 & 0.0432 \\
Between agricultural & Between Nombinnie and agricultural & 0.0190 & 0.0500 \\
Within Nombinnie & Between Nombinnie and agricultural & 0.0002 & 0.0520 \\
\hline
\end{tabular}

Table 5 Probability that slopes and intercepts of regressions of $F_{\mathrm{ST}}$ vs. distance for four classes of pairwise comparisons differ by the observed amount by chance. $P$ values determined using a permutation test with 5000 randomizations

Table 6 Probability that allozyme alleles are identical for all pairwise population comparisons (Raymond \& Rousset 1995b; below diagonal), and Nei (1978) unbiased genetic distance (above diagonal). Significant $(P<0.05)$ values in bold type

\begin{tabular}{lccccccccc}
\hline & G1,2 & P2 & T1,2 & G4 & P4 & T4 & N1,2 & N3 & N4,5,6 \\
\hline G1,2 & - & 0.007 & 0.061 & 0 & 0.13 & 0.075 & 0.045 & 0.008 & 0.07 \\
P2 & 0.2259 & - & 0.05 & 0 & 0.051 & 0.022 & 0.076 & 0.016 & 0.095 \\
T1,2 & $\mathbf{0 . 0 0 0 1}$ & $\mathbf{0 . 0 0 5 8}$ & - & 0.054 & 0.082 & 0.017 & 0.142 & 0.025 & 0.091 \\
G4 & 0.9981 & 0.9991 & 0.6087 & - & 0.033 & 0.012 & 0.057 & 0.037 & 0.105 \\
P4 & $\mathbf{0 . 0 0 2 9}$ & 0.1320 & 0.0595 & 0.7326 & - & 0 & 0.199 & 0.12 \\
T4 & $<\mathbf{0 . 0 0 0 1}$ & 0.1839 & 0.5517 & 0.7303 & 0.8289 & - & 0.235 & 0.062 \\
N1,2 & $\mathbf{0 . 0 4 9 5}$ & $\mathbf{0 . 0 0 0 7}$ & $<\mathbf{0 . 0 0 0 1}$ & 0.1752 & $<\mathbf{0 . 0 0 0 1}$ & $<\mathbf{0 . 0 0 0 1}$ & - & 0.198 \\
N3 & 0.0646 & 0.1905 & $\mathbf{0 . 0 0 5 1}$ & 0.8171 & $\mathbf{0 . 0 2 7 4}$ & $\mathbf{0 . 0 2 3 1}$ & 0.1655 & - & 0.039 \\
N4,5,6 & $<0.0001$ & $<0.0001$ & $<0.0001$ & 0.6632 & 0.0003 & $<0.0001$ & 0.6610 & 0.0092 & - \\
\hline
\end{tabular}

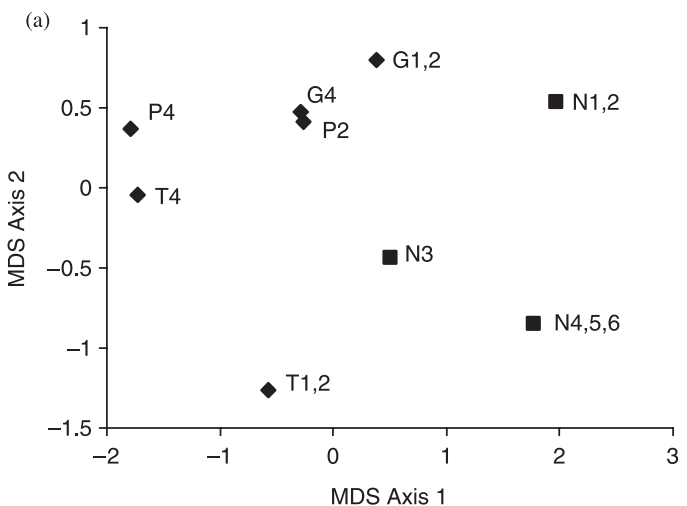

Also, one of the three comparisons among Nombinnie populations indicated a significant difference between sites, whereas there was no evidence of significant divergence between reserves and linear remnant populations within each agricultural location (Table 6).

The two-dimensional ordination and the majority rule consensus tree (Fig. 7) provide some support for the major bifurcation observed in the mtDNA data set. Populations from Nombinnie occupied a distinct area within the twodimensional ordination, although Nombinnie site 3 (N3) was in an intermediate position (Fig. 7a). The consensus tree lacked resolution (Fig. 7b), although it was able to distinguish most of the Nombinnie populations from the agricultural sites. In the full tree (not shown) the most common position for N3 was in a group with the other Nombinnie sites, however, this was only supported by $36 \%$ of bootstrapped replicates.
Fig. 7 (a) Two-dimensional multidimensional scaling of allozyme data (stress $=0.06$, locations indicated by letter, sites by number, see Fig. 1) and (b) majority rule consensus tree (neighbour-joining method) for allozyme data, obtained from 10000 bootstrapped distance matrices [Nei (1978) unbiased genetic distance].

\section{Discussion}

Dispersal

Genetic evidence does not indicate that dispersal by the agamid lizard Amphibolurus nobbi has decreased in agricultural landscapes, and there is some weak evidence suggesting dispersal may have increased. This is despite populations of $A$. nobbi declining and becoming restricted to a small proportion of remnant vegetation (Driscoll 2004). No significant divergence was observed among populations within agricultural landscapes, but there was significant genetic structuring in continuous mallee, raising the possibility that recent dispersal in the farming landscape has increased and not decreased. However, linear strip populations were very small, yielding small sample sizes, so the absence of significant genetic structuring within agricultural 
locations may reflect low power to detect divergence rather than the absence of divergence. Nevertheless, some of the tests comparing linear strip populations with larger populations were significant, indicating that at least large differences were detectable. In addition, small sample sizes produce lower estimates of genetic variation (Leberg 2002), but that is not what we observed.

The observed distribution of $A$. nobbi among remnants also implies effective dispersal. At all three agricultural locations, this species was captured in the reserves and in one category of linear remnant (ungrazed strips with spinifex understorey, Driscoll 2004). It therefore appears that $A$. nobbi occupies all suitable habitat, a pattern that would not be expected if this species had poor colonizing ability (Hanski 1998).

Higher dispersal in the agricultural landscape was also suggested in the isolation-by-distance analysis (Fig. 5, Table 5) with evidence of reduced intercepts and slopes for genetic divergence vs. geographical distance data from the agricultural landscape compared with continuous habitat. However, the between-agricultural-location data had pairwise distances spanning $30-60 \mathrm{~km}$, but the patterns observed at the uncleared Nombinnie site were at a scale of less than $20 \mathrm{~km}$ and so may not represent the slope of the isolation-by-distance pattern at a larger spatial scale in uncleared habitat. Also, the slope of the within-agriculturallocation data was determined by only a small number of data points, so slope in particular may not be reliably represented. We therefore reiterate that our data show very strong evidence for gene flow in the fragmented landscape, at least as high as in continuous mallee, and there is weak evidence that gene flow may actually be higher.

The allozyme data were generally consistent with the patterns of divergence observed in the mitochondrial DNA data set. Although the allozyme data were weakened by small sample sizes and poor resolution, with most common alleles widely distributed (Appendix), the recognition of a main divergence between Nombinnie and the farming landscapes reflects the broad patterns observed in the mtDNA data. It is therefore likely that any genetic structuring observed in mtDNA reflects patterns of dispersal of the entire $A$. nobbi population, and not just females. Application of a high resolution, nuclear gene technique would nevertheless be valuable to test the patterns suggested by the allozyme data.

There are two plausible mechanisms to explain the maintained or possibly increased levels of dispersal, despite population fragmentation. Gilliam \& Fraser (2001) reported that the presence of a strong predator both increased dispersal and fragmented populations of killifish (Rivulus hartii). Movement was enhanced because the killifish moved rapidly through streams with predators (Gilliam \& Fraser 2001). Amphibolurus nobbi may also be motivated to move rapidly out of unsuitable habitat once they enter it, leading to higher dispersal than in continuous habitat. However, if A. nobbi do readily disperse through the farming landscape, then dispersal must only happen occasionally because no dispersers were ever captured over two summers of sampling (Driscoll 2004; unpublished).

An alternative dispersal mechanism that is consistent with genetic evidence is that many of the animals found within small remnants could be refugees from land clearing in the 1970s. Porter (1999) argued that many animals may not be killed during land clearing and may escape into remaining vegetation. Dispersal of 'refugees' increases genetic variation within demes and reduces divergence among demes (Slatkin 1985; Porter 1999). The refugee hypothesis requires that the small populations have remained intact since land clearing largely ceased, about 20 years. It is not known how long $A$. nobbi live, although another Amphibolurus species (A. ornatus) usually lives for less than 3 years (Bradshaw 1971).

Distinguishing between these two models is central to understanding the conservation needs of $A$. nobbi. If the refugee hypothesis is correct, then populations may be isolated and at risk of extinction through demographic stochasticity and genetic deterioration (Lynch et al. 1995; Lande 1998). Deliberate reintroductions may therefore be needed to ensure survival of $A$. nobbi in farming landscapes. In contrast, if there is high dispersal through unsuitable habitat, $A$. nobbi may readily colonize areas of suitable habitat. We would also expect $A$. nobbi to recolonize habitat patches after local extinctions, forming metapopulations (Hanski 1998) or patchy populations (Harrison 1991).

Genetic evidence alone is unable to distinguish between these two scenarios. The timescale of important events is so short that it is not possible to delineate between current gene flow, and the flow of refugees fleeing habitat destruction in past decades. Although other genetic methods could be applied that allow the recognition of very recent migrants (e.g. Stow et al. 2001), such approaches do not always have the necessary resolution (Taylor et al. 1997). Therefore, there remains a need for traditional ecological field methods, including examining social structure and the conditions under which individuals disperse in addition to intensive, direct estimates of dispersal. In combination with genetic results, it may then be possible to build a more solid picture of $A$. nobbi dispersal in extensively cleared landscapes.

Comparisons of levels of genetic variation from reserves in the agricultural matrix with a site in continuous mallee were inconclusive. Although Pulletop showed the expected pattern of reduced genetic variation compared with continuous mallee, Gubbata did not, and Taleeban showed the opposite pattern. Although these patterns may reflect changes to population size and gene flow through the modified landscapes, the interpretation is confounded by the strong phylogeographical patterns in the data set. Local 
differences in haplotype variation could be the product of more ancient dispersal and population dynamics, rather than recent habitat fragmentation.

\section{Historic biogeography}

Driscoll (2004) noted that the zone between Nombinnie and the farming areas might represent range boundaries for nine reptile species. The deep genetic break between A. nobbi from Nombinnie and those from the agricultural locations also suggests that there is a biogeographical discontinuity in that area. Consistent patterns in mtDNA and allozymes suggest that the break represents a physical population bifurcation and is not a product of stochastic clade sorting (Irwin 2002). The absence of isolation by distance but high intercept in comparisons between Nombinnie and agricultural locations (Fig. 5) also implied a historic bifurcation between these groups and not a process of isolation by distance, as observed within both the farming areas and Nombinnie.

The cause of the bifurcation across this region is unknown, but could have arisen through separate colonization of the northern and southern areas as geographical ranges changed in response to shifting climate. Glacial periods lead to more arid conditions (Singh \& Geissler 1985; Field et al. 2002), so with cycles from aridity at glacial maxima to mesic conditions during interglacials, the climatic envelope suited to $A$. nobbi is likely to have shifted in an east-west direction, perpendicular to rainfall isohyets (Australian Bureau of Meteorology, www.bom.gov.au). An alternative or additional mechanism promoting divergence between Nombinnie and populations to the south is the riparian vegetation along the Lachlan River (Fig. 1). Although the river itself dries up and would not form a continual physical barrier, if $A$. nobbi avoids riparian soils and plant communities, dispersal between the two regions may have been inhibited.

The NCA identified patterns of isolation by distance and range expansion among Nombinnie populations. Examination of the geographical distribution of internal and tip haplotypes suggested that range expansion had occurred from the northwestern to the southeastern populations. Although strong natural selection could produce similar genetic patterns, we think that is less likely because there is no evidence of strong environmental clines across the study region (Driscoll 2004). The genetic patterns suggest that $A$. nobbi spatial population dynamics consists of range expansions into new or formerly occupied habitat, followed by periods of stasis, during which isolation by distance promotes genetic divergence. In addition, interpretation of the 3-2 clade implied that long-distance dispersal might contribute to genetic structure. However, without samples between locations, we could not distinguish longdistance dispersal from gradual dispersal.

\section{Conservation}

Applying Moritz's (1994b) definition of evolutionarily significant unit (ESU), the agricultural and Nombinnie clades are separate ESUs because they are reciprocally monophyletic with substantial divergence at nuclear genes. This division is particularly concerning. One ESU may be vulnerable to extinction because it is confined to small remnants in the agricultural zone. We have not surveyed the entire range of $A$. nobbi, so the agricultural ESU may be more widespread. However, extensive habitat clearing extends throughout areas to the south, east and west of the study area, so this ESU may not occur in large, secure tracts of natural habitat. Amphibolurus nobbi has a relatively widespread distribution (Cogger 1996) and is not listed as a threatened species. Nevertheless, the recognition of an ESU that may be confined to the intensive agricultural zone emphasizes that the loss of widespread species from production landscapes can represent a substantial loss of biodiversity, even though the 'species' itself may not be threatened.

The spatial scale of genetic differences indicates the scale at which conservation should occur. If this species declines over areas spanning $20-30 \mathrm{~km}$, then substantial genetic variation will be lost. This is emphasized by the deep (but incompletely sorted) genetic division between the Pulletop and other agricultural locations, and by the restricted distribution of the ND4/tRNA-His duplication. A system of adequately sized reserves in each block of a $400 \mathrm{~km}^{2}$ grid would sample most of the genetic structure of this species. We do not know how large reserves should be to sustain populations in perpetuity. The study reserves are only a few square kilometres, and $A$. nobbi has survived for 2030 years. However, $A$. nobbi abundance is lower in reserves than in continuous mallee (Driscoll 2004), so the reserves may not provide a long-term solution.

In addition to conserving genetic diversity, an important goal of conservation is to maintain evolutionary processes (Driscoll 1998; Moritz 2002). Evolution in A. nobbi appears to involve range expansions, followed by isolation, including isolation by distance, and subsequent divergence. Maintaining connectivity throughout the landscape is therefore essential to achieving biodiversity conservation. Connectivity may be achieved by reconstructing wide corridors with a spinifex understorey away from roads (Driscoll 2004). This may be the only way to connect isolated populations if the refugee hypothesis is the correct dispersal model. On the other hand, if the model of rapid dispersal through unoccupied habitat is correct, then connectivity may be achieved more simply through disturbed linear remnants or re-established corridors. In either case, a carefully stage-managed metapopulation may be required to prevent biodiversity loss from extensively cleared landscapes. Although re-establishing linear vegetation will not 
aid the conservation of several species that cannot use narrow corridors (Driscoll 2004), it would at least improve the outlook for $A$. nobbi in the Australian wheat belt.

\section{Acknowledgements}

Ian Scott and Scott Keogh (ANU) provided advice on DNA extraction and generic primers for reptiles. John Wombey provided access to the collections in the Australian National Wildlife Collection, including the Queensland A. nobbi nobbi. We are grateful for the practical lab advice provided by José ten Have and Margaret Evers. Terry Chesser, A. O. Nicholls and Adam Porter provided helpful comments on an earlier draft. This research was completed under NSW National Parks and Wildlife Service permit A2528 and CSIRO Sustainable Ecosystems Ethics Authority 98/99-06 and -22 . Analysis and write-up of this research was completed while DD held an Australian Research Council Post-Doctoral Fellow in the School of Geography and Environmental Studies at the University of Tasmania.

\section{References}

Altschul SF, Gish W, Miller W, Myers EW, Lipman DJ (1990) Basic local alignment search tool. Journal of Molecular Biology, 215, 403-410.

Avise JC, Arnold J, Ball RM et al. (1987) Intraspecific phylogeography: the mitochondrial DNA bridge between population genetics and systematics. Annual Review of Ecology and Systematics, 18, 489-522.

Bauer J, Goldney D (1999) Extinction processes in a transitional agricultural landscape system. In: Temperate Eucalypt Woodlands in Australia: Biology, Conservation, Management and Restoration (eds Hobbs RJ, Yates CJ), pp. 107-206. Surrey Beatty \& Sons, Chipping Norton, New South Wales.

Bolger DT, Alberts AC, Sauvajot RM et al. (1997) Response of rodents to habitat fragmentation in coastal southern California. Ecological Applications, 7, 552-563.

Bradshaw SD (1971) Growth and mortality in a field population of Amphibolurus lizards exposed to seasonal cold and aridity. Journal of Zoology, 165, 1-25.

Bull JJ, Huelsenbeck JP, Cunningham CW, Swofford DL, Waddell PJ (1993) Partitioning and combining data in phylogenetic analysis. Systematic Biology, 42, 384-397.

Cale PG (2003) The influence of social behaviour, dispersal and landscape fragmentation on population structure in a sedentary bird. Biological Conservation, 109, 237-248.

Clement M, Posada D, Crandell K (2000) Tcs: a computer program to estimate gene genealogies. Molecular Ecology, 9, 1657-1659.

Cogger HG (1996) Reptiles and Amphibians of Australia, 5th edn. Reed Books, Port Melbourne.

Cooper CB, Walters JR, Priddy J (2002) Landscape patterns and dispersal success: simulated population dynamics in the brown treecreeper. Ecological Applications, 12, 1576-1587.

Driscoll DA (1998) Genetic structure, metapopulation processes and evolution influence the conservation strategies for two endangered frog species. Biological Conservation, 83, 43-54.

Driscoll DA (2004) Extinction and outbreaks accompany fragmentation of a reptile community. Ecological Applications, 14, 220-240.

Felsenstein J (1985) Confidence limits on phlylogenies: an approach using the bootstrap. Evolution, 39, 783-791.
Felsenstein J (2001) PHYLIP (Phylogeny Inference Package) version 3.6a2.1. Distributed by the author. Department of Genetics, University of Washington, Seattle.

Field JH, Dodson JR, Prosser IP (2002) A late Pleistocene vegetation history from the Australian semi-arid zone. Quaternary Science Reviews, 21, 1023-1037.

Forstner MRJ, Dixon JR, Forstner JM, Davis SK (1998) Apparent hybridization between Cnemidophorus gularis and Cnemidophorus septemvittatus from an area of sympatry in southwest Texas. Journal of Herpetology, 32, 418-425.

Fraser DJ, Bernatchez L (2001) Adaptive evolutionary conservation: towards a unified concept for defining conservation units. Molecular Ecology, 10, 2741-2752.

Gilliam JF, Fraser DF (2001) Movement in corridors: enhancement by predation threat, disturbance, and habitat structure. Ecology, 82, 258-273.

Good P (1994) Permutation Tests: A Practical Guide to Resampling Methods for Testing Hypotheses. Springer-Verlag, New York.

Gullberg A, Olsson M, Hegelstrom H (1998) Colonization, genetic diversity, and evolution in the Swedish sand lizard, Lacerta agilis (Reptilia, Squamata). Biological Journal of the Linnean Society, 65, 257-277.

Hanski I (1998) Metapopulation dynamics. Nature, 396, 41-49.

Harrison S (1991) Local extinction in a metapopulation context: an empirical evaluation. Biological Journal of the Linnean Society, 42, 73-88.

Hillis DM, Moritz C, Mable BK (1996) Molecular Systematics, 2nd edn. Sinauer Associates, Sunderland, Massachusetts.

Irwin DE (2002) Phylogeographic breaks without geographic barriers to gene flow. Evolution, 56, 2383-2394.

Janke A, Erpenbeck D, Nilsson M, Arnason U (2001) The mitochondrial genomes of the iguana (Iguana iguana) and the caiman (Caiman crocodylus): implications for amniote phylogeny. Proceedings of the Royal Society of London. Series B, Biological Sciences, 268, 623-631.

Kimura M (1980) A simple method for estimating evolutionary rate of base substitutions through comparative studies of nucleotide sequences. Journal of Molecular Evolution, 16, 111-120.

Knutsen H, Rukke BA, Jorde PE, Ims RA (2000) Genetic differentiation among populations of the beetle Bolitophagus reticulatus (Coleoptera: Tenebrionidae) in a fragmented and a continuous landscape. Heredity, 84, 667-676.

Kraus F, Mink DG, Brown WM (1996) Crotaline intergeneric relationships based on mitochondrial DNA sequence data. Copeia, 1996, 763-773.

Kumar S, Tamura K, Jakobsen IB, Nei M (2001) MEGA2: molecular evolutionary genetics analysis software. Bioinformatics, 17, 1244-1245.

Lande R (1998) Anthropogenic, ecological and genetic factors in extinction and conservation. Researches on Population Ecology, 40, 259-269.

Leberg PL (2002) Estimating allelic richness: effects of sample size and bottlenecks. Molecular Ecology, 11, 2445-2449.

Lynch M, Conery J, Burger R (1995) Mutation accumulation and the extinction of small populations. American Naturalist, 146, 489-518.

Moritz C (1994a) Applications of mitochondrial DNA analysis in conservation: a critical review. Molecular Ecology, 3, 401-411.

Moritz C (1994b) Defining 'evolutionarily significant units' for conservation. Trends in Ecology \& Evolution, 9, 373-375.

Moritz C (2002) Strategies to protect biological diversity and the evolutionary processes that sustain it. Systematic Biology, 51, $238-254$ 
Nei M (1978) Estimation of average heterozygosity and genetic distance from a small number of individuals. Genetics, 89, 583-590.

Nei M, Kumar S (2000) Molecular Evolution and Phylogenetics. Oxford University Press, New York.

Nicholas KB, Nicolas HB Jr, Deerfield DW II (1997) GeneDoc: Analysis and Visualization of Genetic Variation. EMBNEW. NEWS 4:14. URL http://www.psc.edu/biomed/genedoc

Porter AH (1999) Refugees from lost habitat and reorganization of genetic population structure. Conservation Biology, 13, 850-859.

Posada D, Crandall KA, Templeton AR (2000) GEODIs: a program for the cladistic nested analysis of the geographical distribution of genetic haplotypes. Molecular Ecology, 9, 487.

Raymond M, Rousset F (1995a) An exact test for population differentiation. Evolution, 49, 1280-1283.

Raymond M, Rousset F (1995b) GENEPOP (version 1.2): population genetics software for exact tests and ecumenicism. Journal of Heredity, 86, 248-249.

Richardson BJ, Baverstock PR, Adams M (1986) Allozyme Electrophoresis: A Handbook for Animal Systematics and Population Studies. Academic Press, Sydney.

Rojas M (1992) The species problem and conservation. What are we protecting? Conservation Biology, 6, 170-178.

Rozas J, Rozas R (1999) DNAsP version 3: an integrated program for molecular population genetics and molecular evolution analysis. Bioinformatics, 15, 174-175.

Saitou N, Nei M (1987) The neighbor-joining method: a new method for reconstructing phylogenetic trees. Molecular Biology and Evolution, 4, 406-425.

Sambrook J, Fritsch EF, Maniatis T (1989) Molecular Cloning: A Laboratory Manual. Cold Spring Harbor Laboratory Press, Cold Spring Harbor, New York.

Saunders DA, Hobbs RJ, Margules CR (1991) Biological consequences of ecosystem fragmentation: a review. Conservation Biology, 5, 18-32.

Schneider S, Roessli D, Excoffier L (2000) ARLEQUIN, Version 2.000: a software for population genetics analysis. Genetics and Biometry Laboratory, Department of Anthropology, University of Geneva, Switzerland.

Schuler G, Epstein JA, Ohkawa H, Kans JA (1996) ENTREZ: molecular biology database and retrieval system. Methods in Enzymology, 266, 141-162.

Scott IAW, Keogh JS (2000) Conservation genetics of the endangered grassland earless dragon, Tympanocryptis pinguicolla (Reptilia: Agamidae) in southeastern Australia. Conservation Genetics, 1, 357-363.

Shaw PW, Turan C, Wright JM, O'Connell M, Carvalho GR (1999) Microsatellite DNA analysis of population structure in Atlantic herring (Clupea harengus), with direct comparison to allozyme and mtDNA RFLP analyses. Heredity, 83, 490-499.

Singh G, Geissler EA (1985) Late Cainozoic history of vegetation, fire, lake levels and climate, at Lake George, New South Wales, Australia. Philosophical Transactions of the Royal Society of London. Series B, Biological Sciences, 311, 379-447.

Sivertsen D, Metcalfe L (1995) Natural vegetation of the southern wheat belt (Forbes and Cargelligo 1: 250000 map sheets). Cunninghamia, 4, 103-128.
Slatkin M (1985) Gene flow in natural populations. Annual Review of Ecology and Systematics, 16, 393-430.

Stow AJ, Sunnucks P, Briscoe DA, Gardner MG (2001) The impact of habitat fragmentation on dispersal of Cunningham's skink (Egernia cunninghami): evidence from allelic and genotypic analyses of microsatellites. Molecular Ecology, 10, 867-878.

Swofford DL (2002) PAUP*. Phylogenetic Analysis Using Parsimony (*and Other Methods), Version 4. Sinauer Associates, Sunderland, Massachusetts.

Swofford DL, Selander RB, Black WC (1997) BIosYs-2: a computer program for the analysis of allelic variation in genetics. Department of Genetics and Development, University of Illinois at UrbanaChampaign, Urbana, Illinois.

Tajima F (1989) Statistical methods to test for nucleotide mutation hypothesis by DNA polymorphism. Genetics, 123, 585-595.

Taylor AC, Horsup A, Johnson CN, Sunnucks P, Sherwin B (1997) Relatedness structure detected by microsatellite analysis and attempted pedigree reconstruction in an endangered marsupial, the northern hairy-nosed wombat Lasiorhinus krefftii. Molecular Ecology, 6, 9-19.

Templeton AR (1998) Nested clade analysis of phylogeographic data: testing hypotheses about gene flow and population history. Molecular Ecology, 7, 381-397.

Templeton AR (2004) Statistical phylogeography: methods of evaluating and minimizing inference errors. Molecular Ecology, 13, 789-809.

Templeton AR, Boerwinkle E, Sing CF (1987) A cladistic analysis of phenotypic associations with haplotypes inferred from restriction endonuclease mapping. I. Basic theory and an analysis of alcohol dehydrogenase activity in Drosophila. Genetics, 117, 343-351.

Templeton AR, Sing CF (1993) A cladistic analysis of phenotypic associations with haplotypes inferred from restriction endonuclease mapping. IV. Nested analyses with cladogram uncertainty and recombination. Genetics, 134, 659-669.

Weir BS, Cockerham CC (1984) Estimating F-statistics for the analysis of population structure. Evolution, 38, 1358-1370.

Williams BL, Brawn JD, Paige KN (2003) Landscape scale genetic effects of habitat fragmentation on a high gene flow species: Speyeria idalia (Nymphalidae). Molecular Ecology, 12, 11-20.

Witten GJ (1974) Population movements of the agamid lizard Amphibolurus nobbi. Australian Zoologist, 18, 129-132.

Wright S (1931) Evolution in Mendelian populations. Genetics, 16, 97-159.

Don Driscoll studies the ecology and genetics of habitat fragmentation and biodiversity conservation. He collected genetic data as a postdoc with CSIRO Sustainable Ecosystems, wrote it up as an Australian Research Council Postdoctoral Fellow at the University of Tasmania and is now lecturing in biodiversity at Flinders University, South Australia. Chris Hardy is a Senior Research Scientist with CSIRO Sustainable Ecosystems and his main interests are in the areas of molecular evolution of vertebrates and the reproductive genetics of mammals. 


\section{Appendix}

Table of sample sizes for eight allozyme loci, and allele frequencies for nine Amphibolurus nobbi sites

\begin{tabular}{|c|c|c|c|c|c|c|c|c|c|}
\hline & $\mathrm{G} 1,2$ & P2 & $\mathrm{T} 1,2$ & G4 & P4 & $\mathrm{T} 4$ & $\mathrm{~N} 1,2$ & N3 & $\mathrm{N} 4,5,6$ \\
\hline \multicolumn{10}{|c|}{ PepB: Peptidase B (leucine glycine glycine), E.C. number 3.4.11 } \\
\hline$(N)$ & 17 & 9 & 15 & 2 & 3 & 2 & 3 & 10 & 17 \\
\hline 1 & 0.059 & 0.000 & 0.000 & 0.000 & 0.000 & 0.000 & 0.000 & 0.050 & 0.029 \\
\hline 2 & 0.382 & 0.167 & 0.467 & 0.250 & 0.000 & 0.500 & 0.000 & 0.300 & 0.088 \\
\hline 3 & 0.412 & 0.611 & 0.467 & 0.750 & 0.833 & 0.500 & 0.833 & 0.450 & 0.647 \\
\hline 4 & 0.147 & 0.222 & 0.067 & 0.000 & 0.167 & 0.000 & 0.167 & 0.200 & 0.235 \\
\hline \multicolumn{10}{|c|}{ PepC: Peptidase C (valine leucine), 3.4.11 } \\
\hline$(N)$ & 17 & 8 & 14 & 2 & 3 & 2 & 4 & 10 & 20 \\
\hline 1 & 0.265 & 0.125 & 0.143 & 0.250 & 0.167 & 0.000 & 0.125 & 0.200 & 0.100 \\
\hline 2 & 0.735 & 0.813 & 0.857 & 0.750 & 0.833 & 1.000 & 0.875 & 0.800 & 0.900 \\
\hline 3 & 0.000 & 0.063 & 0.000 & 0.000 & 0.000 & 0.000 & 0.000 & 0.000 & 0.000 \\
\hline \multicolumn{10}{|c|}{ PepD: Peptidase D (phenylalanyl-proline), 3.4.11 } \\
\hline$(N)$ & 16 & 8 & 14 & 1 & 3 & 2 & 4 & 10 & 19 \\
\hline 1 & 0.000 & 0.000 & 0.036 & 0.000 & 0.000 & 0.000 & 0.000 & 0.000 & 0.000 \\
\hline 2 & 0.063 & 0.250 & 0.143 & 0.000 & 0.167 & 0.250 & 0.000 & 0.200 & 0.053 \\
\hline 3 & 0.188 & 0.000 & 0.393 & 0.000 & 0.167 & 0.000 & 0.500 & 0.400 & 0.684 \\
\hline 4 & 0.688 & 0.750 & 0.357 & 1.000 & 0.667 & 0.750 & 0.500 & 0.400 & 0.158 \\
\hline 5 & 0.063 & 0.000 & 0.071 & 0.000 & 0.000 & 0.000 & 0.000 & 0.000 & 0.079 \\
\hline 6 & 0.000 & 0.000 & 0.000 & 0.000 & 0.000 & 0.000 & 0.000 & 0.000 & 0.026 \\
\hline \multicolumn{10}{|c|}{$\alpha$ Est: Alpha Esterase, 3.1.1.1 } \\
\hline$(N)$ & 17 & 7 & 14 & 4 & 3 & 6 & 8 & 12 & 20 \\
\hline 1 & 0.176 & 0.214 & 0.464 & 0.250 & 0.333 & 0.667 & 0.000 & 0.333 & 0.200 \\
\hline 2 & 0.735 & 0.571 & 0.214 & 0.500 & 0.000 & 0.000 & 1.000 & 0.625 & 0.775 \\
\hline 3 & 0.088 & 0.214 & 0.321 & 0.250 & 0.667 & 0.333 & 0.000 & 0.042 & 0.025 \\
\hline \multicolumn{10}{|c|}{ Pgm: Phosphoglucomutase, 2.7.5.1 } \\
\hline$(N)$ & 17 & 8 & 15 & 2 & 3 & 6 & 3 & 10 & 16 \\
\hline 1 & 0.000 & 0.000 & 0.067 & 0.000 & 0.000 & 0.000 & 0.000 & 0.000 & 0.125 \\
\hline 2 & 1.000 & 1.000 & 0.933 & 1.000 & 1.000 & 1.000 & 1.000 & 0.950 & 0.750 \\
\hline 3 & 0.000 & 0.000 & 0.000 & 0.000 & 0.000 & 0.000 & 0.000 & 0.050 & 0.125 \\
\hline \multicolumn{10}{|c|}{ Pgi: Glucosephosphate isomerase, 5.3.1.9 } \\
\hline$(N)$ & 22 & 8 & 15 & 4 & 3 & 6 & 7 & 2 & 20 \\
\hline 1 & 0.045 & 0.000 & 0.000 & 0.000 & 0.000 & 0.000 & 0.071 & 0.000 & 0.000 \\
\hline 2 & 0.955 & 1.000 & 1.000 & 1.000 & 1.000 & 1.000 & 0.857 & 0.750 & 0.950 \\
\hline 3 & 0.000 & 0.000 & 0.000 & 0.000 & 0.000 & 0.000 & 0.071 & 0.250 & 0.050 \\
\hline \multicolumn{10}{|c|}{ Mpi: Mannose phosphate isomerase, 5.3.1.8 } \\
\hline$(N)$ & 18 & 9 & 14 & 2 & 3 & 2 & 4 & 10 & 20 \\
\hline 1 & 0.000 & 0.000 & 0.000 & 0.000 & 0.500 & 0.250 & 0.000 & 0.050 & 0.025 \\
\hline 2 & 1.000 & 1.000 & 1.000 & 1.000 & 0.500 & 0.750 & 1.000 & 0.950 & 0.975 \\
\hline \multicolumn{10}{|c|}{$\alpha G p d:$ alpha-Glycerolphosphate dehydrogenase, 1.1.1.8 } \\
\hline$(N)$ & 21 & 7 & 13 & 4 & 3 & 4 & 6 & 12 & 19 \\
\hline 1 & 0.024 & 0.071 & 0.346 & 0.000 & 0.000 & 0.000 & 0.083 & 0.083 & 0.079 \\
\hline 2 & 0.452 & 0.643 & 0.462 & 0.500 & 0.667 & 0.750 & 0.083 & 0.500 & 0.342 \\
\hline 3 & 0.429 & 0.286 & 0.192 & 0.500 & 0.333 & 0.250 & 0.583 & 0.125 & 0.526 \\
\hline 4 & 0.095 & 0.000 & 0.000 & 0.000 & 0.000 & 0.000 & 0.250 & 0.292 & 0.053 \\
\hline
\end{tabular}

